\title{
Transaction
}

\section{Synthesis of HIV Vaccine Model Based on Lactose-Functionalized Poly(lysine) Dendrimer Scaffold}

\author{
Huricha Baigude $^{* 1}$, Kaname Katsuraya ${ }^{\star 2}$,Kohsaku Okuyama ${ }^{* 3}$, \\ Naoki Kariya ${ }^{* 1}$, and Toshiyuki Uryu ${ }^{* 1}$ \\ "Department of Environmental and Material Engineering, Teikyo University of \\ Science \& Technology, 2525 Yatsusawa, Uenohara, Yamanashi 409-0193; \\ ${ }^{* 2}$ Wayo Women's University, 2-3-1 Konodai, Ichikawa, Chiba 272-8533; \\ ${ }^{* 3}$ Institute of Industrial Science, University of Tokyo, Komaba, Meguro-ku, \\ Tokyo 153-8505, Japan
}

\begin{abstract}
A series of HIV vaccine models based on lactose-bound poly(lysine) scaffolds was synthesized. A spherical poly(lysine) dendrimer was prepared to bind lactose at the peripheral through reductive amination. Lactose-poly(lysine) dendrimers with the degree of substitution (DS) varying from 5 to 19 were obtained by controlling the feeding ratio of lactose to the poly(lysine) dendrimer. Three succinylated compounds such as succinyl monobenzylate, ethylphenylalanyl succinylamide and succinyl-L-alanyl-L-prolyl-L-alanine p-nitroanilide which were regarded as antigen peptide models were bound to the lactose-poly(lysine) dendrimer through esterification between the carboxyl group of the succinyl moiety and the 6-OH group of the lactose residue. The degree of substitution (DS) of resulting vaccine models was investigated by NMR spectra analyses.
\end{abstract}

(Received 12 September, 2003; Accepted 10 December, 2003)

\section{Introduction}

Synthesis of dendrimers for biomedical purpose has been attracting attention recently. With multiple peripheral groups and well-define structure, the dendrimer provides beneficial characteristics for drug or antigen delivery system. ${ }^{1-5}$

In recent examples, sugar-containing dendrimers, or saccharide-functionalized dendrimers are of great interest because the sugar moiety in these dendrimers is believed to play important role in cell recognition and adhension. ${ }^{6-9}$ Aoi et al reported the synthesis and recognition ability of lactose- or maltose-substituted poly(amidoamine) dendrimer (PAMAM).$^{10}$ Okada et al synthesized galactose and $\mathrm{N}$-acetylglucosamine-bound PAMAM, and studied the ability of the dendrimers to recognize a naphthalenesulfonate salt and inhibit wheat germ agglutinin. ${ }^{11}$ Woller et al reported lectin-binding activity of a mannose/hydroxyl-functionalized PAMAM dendrimer. ${ }^{12}$

We have been investigating synthesis and bioactivity of sugar-containing dendrimer vaccine against HIV (human immunodeficiency virus). ${ }^{13}$ Monodispersed oligosaccharide-poly(lysine) dendrimers and highlysubstituted oligosaccharide-poly(ornithine) dendrimers were synthesized as antigen delivery candidate for HIV vaccine. ${ }^{14,15}$ To control the number of terminal sugars in the following step, amino acid proline having monofunctional $\mathrm{NH}$ group was connected to the amino group of the poly(lysine) dendrimer. ${ }^{16}$ The purpose of binding sugar to the surface of polypeptide dendrimer is to increase the biocompatibility of the dendrimer and to facilitate the binding of an HIV antigen, because polypeptide dendrimers may have potential toxicity and immunogenicity, like commercially available PAMAM dendrimer and poly(propyleneimine) dendrimer. ${ }^{17,18}$ However, excess amount of sugar in the dendrimer might have negative aspects such as decreased solubility in organic solvent, hence making the deprotection of antigen peptide impossible in the following work. ${ }^{19}$

In this paper, we wish to report the synthesis of dendrimer-type HIV vaccine models using lowly substituted spherical lactose-poly(lysine) dendrimer and low molecular weight model compounds. Structure of the dendrimer vaccine models was examined by ${ }^{1} \mathrm{H}$ NMR spectroscopy and MALDI-TOF mass spectrometry.

\section{Experimental}

\subsection{Materials and measurements}

1, 4-Diaminobutane dihydrochloride, succinic 
anhydride, $L(+)$-lysine hydrochloride and boranepyridine complex were purchased from Kanto Chemical Co., Inc. $\beta$-D-Lactose, $N, N^{\prime}$-diisopropylethylamine (DIEA), benzotriazol-1-yloxytris-(dimethylamino) phosphonium hexafluorophosphate (BOP reagent), 4(dimethylamino)pyridine (DMAP), 1-ethyl-3-(3dimethylaminopropyl)carbodiimide hydrochloride (EDC) and $N, N^{\prime}$-dicyclohexylcarbodiimide (DCC) were used as received. Succinyl-L-alanyl-L-prolyl-L-alanine p-nitroanilide was purchased from Peptide Institute, Inc. Dimethyl sulfoxide (DMSO) and $N, N^{\prime}$ dimethylformamide (DMF) were distilled after drying. $N, N$ '-Bis(t-butyloxycarbonyl)-lysine dicyclohexylamine salt (Boc-lysine(Boc)-COOH) and spherical poly(lysine) dendrimer G3 (SLD) were prepared according to the literature. ${ }^{14}$ A dialyzing tube (MWCO 1000; Spectrum Laboratories, Inc.) was used for the purification of sugar-containing poly(lysine) dendrimers. ${ }^{1} \mathrm{H}$ NMR spectra were recorded on a JEOL Alpha-500 NMR spectrometer. Chemical shifts $(\delta=0 \mathrm{ppm})$ were referred to TMS with the residual proton of the solvents. Matrixassisted laser desorption/ionization time-of-flight mass spectrometry (MALDI-TOF MS) spectra were recorded on a Bruker Biflex III instrument with a 337-nm nitrogen laser. $\alpha$-Cyano-4-hydroxy-cinnamic acid (5 $\mathrm{mg} / 100 \mu \mathrm{L}$ water solution) was used as matrix. A mixture of the sample solution ( $1 \mu \mathrm{L}, 0.5 \mathrm{mg} / \mathrm{ml}$ in 0.1 trifluoroacetic acid) and the matrix solution was applied to the MALDI probe. The sample was allowed to dry by air evaporation, followed by subjecting to MS analysis.

2.2 Synthesis of lactose-poly(lysine) dendrimer generation 3 (LLD)

Lactose was bound to spherical poly(lysine) dendrimer $\mathrm{G} 3$ in a feeding ratio ranging from 0.3 to 2.0 between lactose and amino group on the peripheral of the dendrimer. A typical reaction is as follows. Spherical poly(lysine) dendrimer G3 $(0.21 \mathrm{~g}, 0.06 \mathrm{mmol})$ was deprotected and dissolved in $10 \mathrm{ml} 0.2 \mathrm{M}$ borate buffer (pH 9.0). Lactose $(0.33 \mathrm{~g}, 0.96 \mathrm{mmol})$ and boranepyridine complex $(0.1 \mathrm{ml}, 0.96 \mathrm{mmol})$ was added to the above solution. The solution was stirred in an oil bath at $50{ }^{\circ} \mathrm{C}$ for $7 \mathrm{~d}$. The resulting compound was purified by dialysis against pure water for $3 \mathrm{~d}$. A white powdery lactose-poly(lysine) dendrimer generation 3 (0.258 g) was obtained by freeze-drying. Yield: $60.5 \%$.

\subsection{Preparation of succinyl monobenzylate}

Succinic anhydride $(2.0 \mathrm{~g}, 20 \mathrm{mmol})$ and benzyl alcohol $(1.9 \mathrm{ml}, 20 \mathrm{mmol})$ were reacted in pyridine $(20$ $\mathrm{ml}$ ) at room temperature for $20 \mathrm{~h}$. Concentrated material was purified by column chromatography over silica gel using a mixture of chloroform and methanol (10:1) as eluent. A white solid product $(3.26 \mathrm{~g})$ was obtained in $87 \%$ yield.

\subsection{Preparation of ethyl-phenylalanyl succinylamide}

To a phenylalanine ethyl ester (1.0 g, $4.4 \mathrm{mmol})$ solution in $20 \mathrm{ml}$ pyridine, succinic anhydride $(0.37 \mathrm{~g}$, $3.7 \mathrm{mmol}$ ) was added, followed by stirring overnight at room temperature. After concentration, the resulting syrup was dissolved in chloroform and washed with 0.5 $\mathrm{N} \mathrm{HCl}$ solution 3 times. The chloroform solution was dried on anhydrous $\mathrm{Na}_{2} \mathrm{SO}_{4}$ and condensed to give a white solid product ( $1.07 \mathrm{~g})$. Yield: $93 \%$.

2.5 Synthesis of succinyl monobenzylate-lactosepoly(lysine) dendrimer G3 (SBLD)

LLD (DS: $19,80 \mathrm{mg}$ ) was completely dissolved by stirring in DMSO $(3 \mathrm{ml})$ at $50{ }^{\circ} \mathrm{C}$ for $36 \mathrm{~h}$. Succinyl monobenzylate (35 mg, $0.18 \mathrm{mmol}$ ) and DMAP (45 mg, $0.36 \mathrm{mmol})$ were added to the solution. After DCC (190 $\mathrm{mg}, 0.92 \mathrm{mmol}$ ) was added, the solution was stirred at room temperature for $24 \mathrm{~h}$. After work-up, white powdery succinyl monobenzylate-lactose-poly(lysine) dendrimer G3 (83 $\mathrm{mg}$ ) was obtained by drying the precipitate in oven under reduced pressure.

2.6 Synthesis of ethyl-phenylalanyl
succinylamide-lactose-poly(lysine) dendrimer
G3 (PASLD)

To a LLD (DS: $16,48 \mathrm{mg}$ ) solution in DMSO $(3 \mathrm{ml})$ were added ethyl-phenylalanyl succinylamide $(36 \mathrm{mg}$, $0.12 \mathrm{mmol}$ ) and DMAP ( $31 \mathrm{mg}, 0.25 \mathrm{mmol}$ ). After DCC (130 mg, $0.63 \mathrm{mmol}$ ) was added, the solution was stirred at room temperature for $24 \mathrm{~h}$. Ethyl acetate was added to the solution until precipitates appeared. The precipitate was collected by centrifugation and successively washed with ethyl acetate, ethanol, acetone and methanol. A white powdery ethyl-phenylalanyl succinylamidelactose-poly(lysine) dendrimer G3 (55 mg) was obtained after freeze-drying from water.

2.7 Synthesis of alanyl-prolyl-alanine-succinyllactose-poly(lysine) dendrimer G3 (APASD)

Succinyl-L-alanyl-L-prolyl-L-alanine p-nitroanilide ( $56 \mathrm{mg}, 0.12 \mathrm{mmol}$ ) was addedato a solution of lactosepoly(lysine) dendrimer G3 (DS: $19,53 \mathrm{mg}$ ) and DMAP (29 mg, $0.24 \mathrm{mmol}$ ). DCC (126 mg, $0.61 \mathrm{mmol}$ ) was added and the solution was stirred for $24 \mathrm{~h}$ atroom temperature. Then, ethyl acetate was added until precipitates appeared. The precipitate was collected by centrifugation, followed by purifying with the same method as above. A light yellow powdery alanyl-prolylalanine-succinyl-lactose-poly(lysine) dendrimer G3 (57 
mg) was obtained after freeze-drying.

\section{Results and discussion}

\subsection{Synthesis of lactose-poly(lysine) dendrimer} generation 3

The influence of feeding ratio of lactose to the peripheral amino group on the degree of substitution of resulting glyco-peptide dendrimer was investigated. In ${ }^{1} \mathrm{H}$ NMR spectra shown in Figure 1 , since the absorptions in the range of 2.8 to $3.2 \mathrm{ppm}$ are due to those of $\varepsilon-\mathrm{CH}_{2}$ of lysine side chain and $\mathrm{CH}_{2}-1$ ' of the connected lactose, it was revealed that the absorption intensity represents the degree of substitution by lactose.

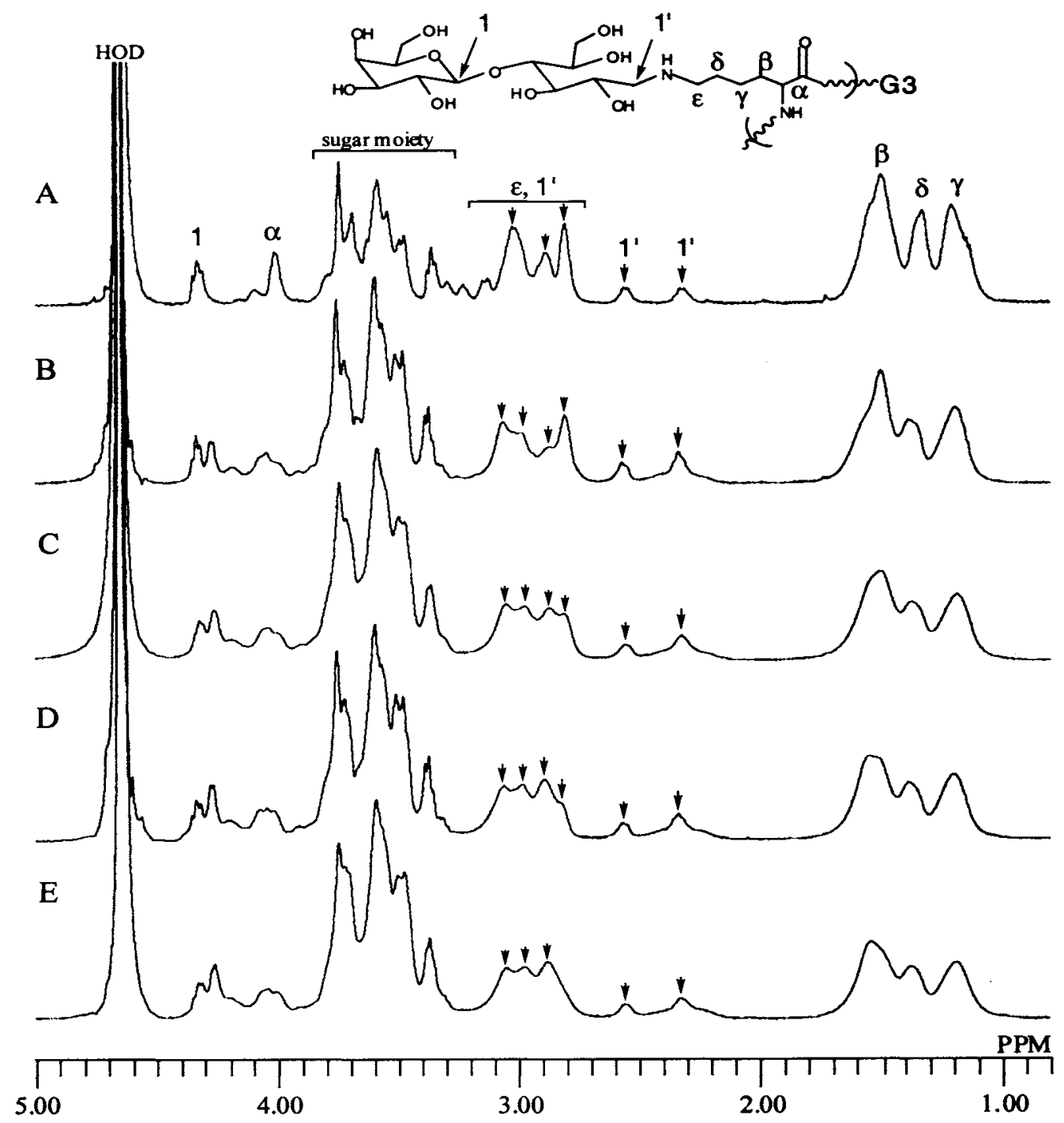

Fig. $1{ }^{1} \mathrm{H}$ NMR spectra of lactose-poly(lysine) dendrimer G3 (LLD) in $\mathrm{D}^{2} \mathrm{O}$ (A. DS: 5.5; B. DS: 11.6; C. DS: 13.5; D. DS: 15.0; E. DS: 19.7).

Peaks corresponding to $\alpha-, \beta-, \gamma-, \delta$ - and $\varepsilon$-protons of lysine residues in the poly(lysine) dendrimer and lactose residues were observed in ${ }^{1} \mathrm{H}$ NMR spectra. Absorptions due to peripheral $\varepsilon-\mathrm{CH}_{2}$ connected to a unreacted $\mathrm{NH}_{2}$ group and $\varepsilon-\mathrm{CH}_{2}$ connected to a lactose-substituted $\mathrm{NH}$ group appeared at $2.8 \mathrm{ppm}$ and $2.9 \mathrm{ppm}$, respectively. On the other hand, the $\varepsilon-\mathrm{CH}_{2}$ group positioned at inner layer appeared around $3.1 \mathrm{ppm}$. New peaks for $\mathrm{Hl}$ ' of the lactose residue were observed separately at $2.3 \mathrm{ppm}$, $2.5 \mathrm{ppm}$ and $2.98 \mathrm{ppm}$. With the increase of DS of lactose, the peak at $2.8 \mathrm{ppm}$ decreased, while the peaks at $2.3 \mathrm{ppm}, 2.5 \mathrm{ppm}, 2.9 \mathrm{ppm}$ and $2.98 \mathrm{ppm}$ increased. Thus, it was found that the number of lactose residues coupled to peripheral $\mathrm{NH}$ groups increased with increasing ratio of lactose in feed.

Both the degree of substitution (DS) and the yield increased with an increase in feeding ratio of lactose up to 1.4 , while the increasing rate of DS slowed down and the yield reached to nearly constant beyond 1.4 (Figure 2 ). This indicates that the binding of lactose by reductive 
amination became difficult after an average of one lactose residue coupled to the individual amino group.

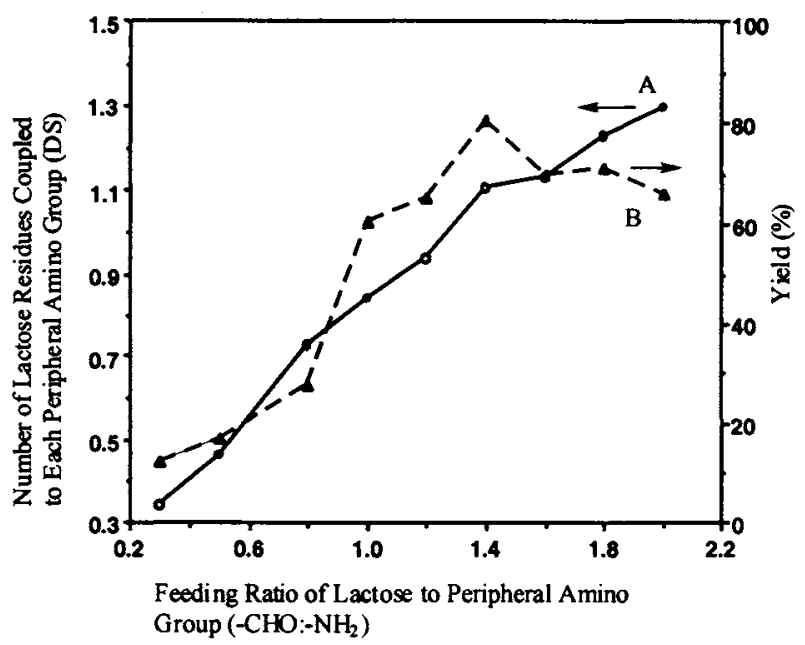

Fig. 2 Effect of feeding ratio between lactose and peripheral amino group of poly(lysine) dendrimer G3 on the degree of substitution (A) and yield $(\mathrm{B})$.

MALDI-TOF MS spectrum revealed that the lactose-poly(lysine) dendrimer prepared in the feeding ratio $\left(\left[-\mathrm{NH}_{2}\right] /[-\mathrm{CHO}]=1: 2\right)$ contained seven isomeric dendrimers having different molecular weights (Figure $3)$. The peaks at $7100.34,7427.94,7773.25,8100.54$, $8412.16,8762.65$ and $9079.74 \mathrm{~g} / \mathrm{mol}$ correspond to lactose-poly(lysine) dendrimer generation 3 containing $16,17,18,19,20,21,22$ lactose residues, respectively, with the $8100.54 \mathrm{~g} / \mathrm{mol}$ (DS:19) peak being the most abundant peak.

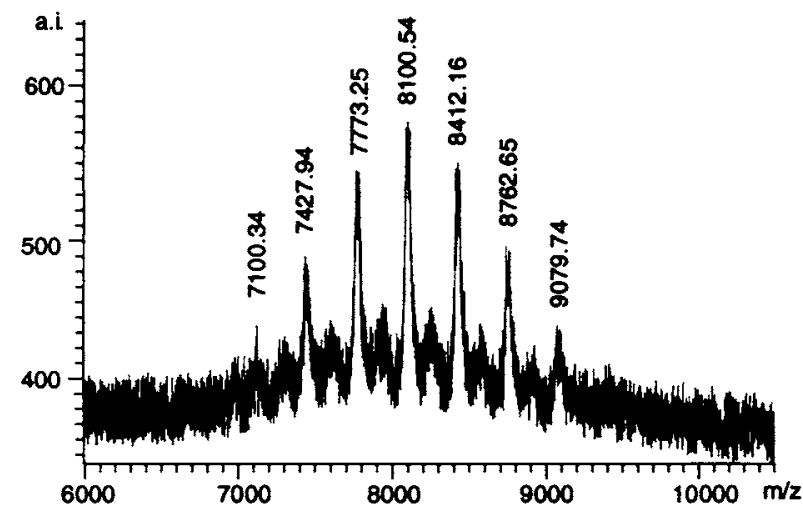

Fig. 3 MALDI-TOF mass spectrum of lactosepoly(lysine) dendrimer G3 (LLD) with DS 19.

Results of the synthesis of the lactose-poly(lysine) dendrimer generation 3 are summarized in Table 1. For dendrimers having low degree of substitution, their DS were higher than the feeding ratio and the yield was considerably low. For example, DS in run No. 1 in Table 1 was 5.5 , being higher than the expected maximum DS of 4.8. Because the dendrimer had spherical structure, it may have passed during dialysis through membrane with small cut-off molecular weight.

Table 1 Synthesis of lactose-poly(lysine) dendrimer generation 3. a)

\begin{tabular}{|c|c|c|c|c|c|c|c|c|c|c|}
\hline \multirow[b]{2}{*}{ No. } & \multicolumn{3}{|c|}{ SLD $^{\text {b) }}$} & \multicolumn{3}{|c|}{ lactose } & \multicolumn{2}{|c|}{$\mathrm{BH}_{3} /$ pyridine } & \multirow{2}{*}{$\begin{array}{l}\text { yield } \\
g(\%)\end{array}$} & \multirow[b]{2}{*}{$D S^{d)}$} \\
\hline & g & $\mathrm{mmol}$ & $-\mathrm{NH}_{2}$ & g & $\mathrm{mmol}$ & eq. ${ }^{c)}$ & $\mathrm{ml}$ & mmol & & \\
\hline 1 & 0.21 & 0.06 & 0.96 & 0.10 & 0.29 & 0.3 & 0.03 & 0.29 & $0.025(12.1)$ & 5.5 \\
\hline 2 & 0.21 & 0.06 & 0.96 & 0.16 & 0.48 & 0.5 & 0.05 & 0.48 & $0.045(16.7)$ & 7.4 \\
\hline 3 & 0.21 & 0.06 & 0.96 & 0.26 & 0.77 & 0.8 & 0.08 & 0.77 & $0.098(27.3)$ & 11.6 \\
\hline 4 & 0.21 & 0.06 & 0.96 & 0.33 & 0.96 & 1.0 & 0.10 & 0.96 & $0.258(60.5)$ & 13.5 \\
\hline 5 & 0.21 & 0.06 & 0.96 & 0.39 & 1.15 & 1.2 & 0.12 & 1.15 & $0.318(65.2)$ & 15.0 \\
\hline 6 & 0.21 & 0.06 & 0.96 & 0.46 & 1.34 & 1.4 & 0.14 & 1.34 & $0.443(80.4)$ & 17.7 \\
\hline 7 & 0.21 & 0.06 & 0.96 & 0.52 & 1.54 & 1.6 & 0.16 & 1.54 & $0.430(70.0)$ & 18.1 \\
\hline 8 & 0.21 & 0.06 & 0.96 & 0.59 & 1.73 & 1.8 & 0.18 & 1.73 & $0.483(71.3)$ & 19.7 \\
\hline 9 & 0.21 & 0.06 & 0.96 & 0.66 & 1.92 & 2.0 & 0.20 & 1.92 & $0.487(65.9)$ & 20.8 \\
\hline
\end{tabular}

a) The reaction was conducted in a borate buffer $(0.2 \mathrm{M}, \mathrm{pH} 9.0)$. The temperature was $50{ }^{\circ} \mathrm{C}$. The time was 7 days. ${ }^{\text {b) }}$ Spherical poly(lysine) dendrimer generation 3 was deprotected before use. ${ }^{\text {c) }}$ Equivalent to one peripherial amino group of SLD. ${ }^{\text {d) }}$ Degree of substitution was estimated from ${ }^{1} \mathrm{H}$ NMR measurement. 


\subsection{Synthesis of vaccine models}

To investigate the reaction between lactosepoly(lysine) dendrimer G3 and an antigen peptide model with different molecular weight, vaccine models were synthesized by binding succinyl-monobenzylate, ethylphenylalanyl succinylamide or succinyl-alanyl-prolylalanine-p-nitroanilide to $\mathrm{OH}$ group of the lactose residue of lactose-poly(lysine) dendrimer G3 through ester

linkage (Figure 4). Although it was difficult to dissolve lactose-poly(lysine) dendrimers in organic solvents at room temperature, the dendrimers dissolved in DMSO after stirring at $50{ }^{\circ} \mathrm{C}$ for $24 \mathrm{~h}$. The resulting oligopeptide-linked dendrimers were easily separated and purified by precipitation.

Fig. 4 Synthesis of alanyl-prolyl-alanine-succinyl-lactose-poly(lysine) dendrimer generation 3 (APASD).

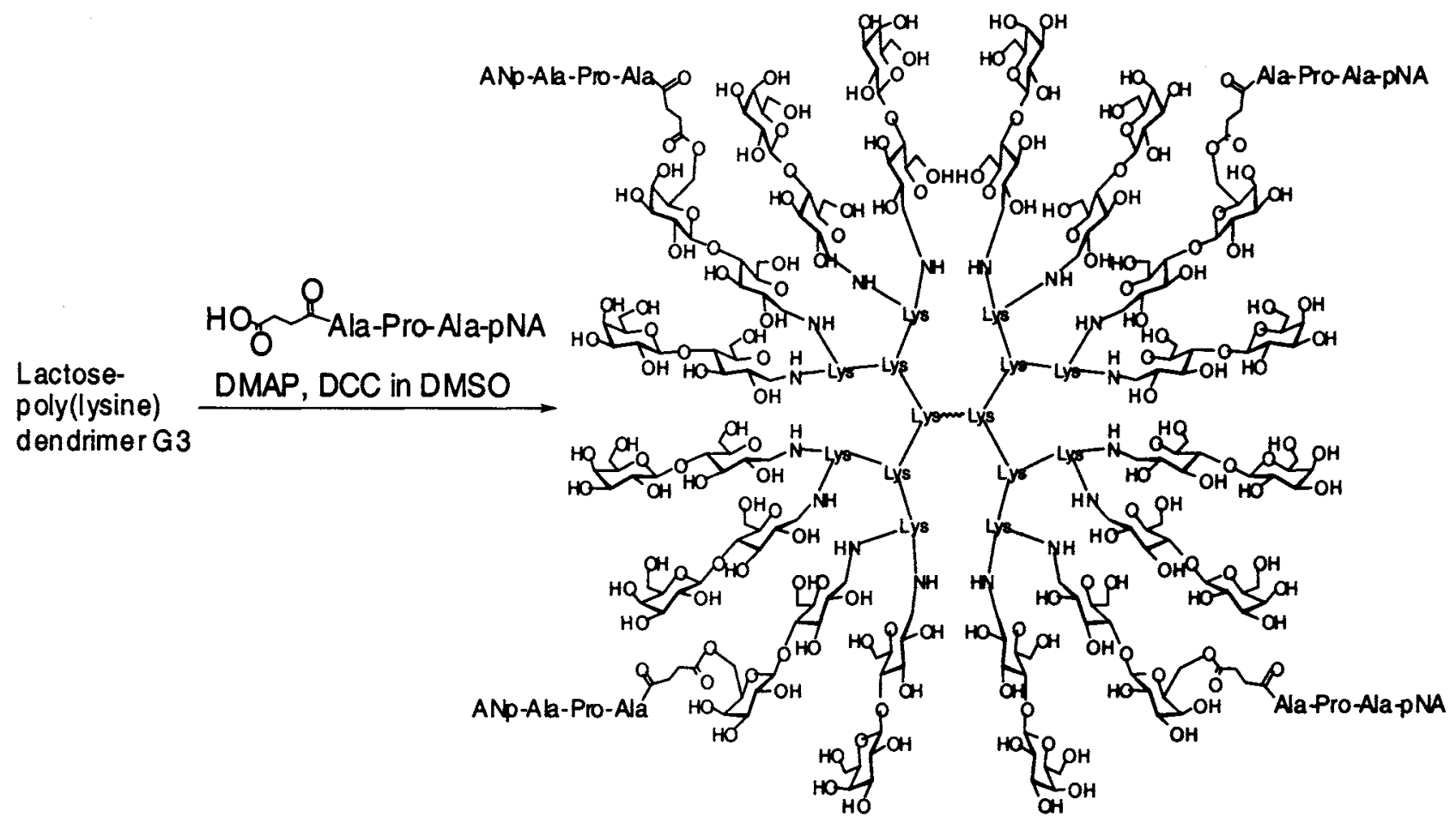

pNA-Ala-Pro-Ala-succinyl-lactose-polyllysine) dendrimer G3 (APASD) $=-\mathrm{NH}^{\mathrm{N}}-\mathrm{CH}_{2}-\mathrm{CH}_{2}-\mathrm{CH}_{2}-\mathrm{CH}_{2}-\mathrm{NH}$

The ${ }^{1} \mathrm{H}$ NMR spectra of these vaccine models show peaks corresponding to the poly(lysine) dendrimer, lactose moiety and model antigen compounds (Figure 5). It was revealed that an average of 4 to 8 antigen compounds were bound to each lactose-poly(lysine) dendrimer G3. Accordingly, the lactose-poly(lysine) dendrimer $\mathrm{G} 3$ reacted with antigen peptide having a free $\mathrm{COOH}$ group. A dendrimer-type HIV vaccine can be synthesized by binding a long antigen peptide sequence to lactose-poly (lysine) dendrimer G3 in a similar method.

The degree of substitution of a tripeptide succinyl-Lalanyl-L-prolyl-L-alanine p-nitroanilide (DS: 4) is apparently lower than amino acid derivative (DS: 8), although both compounds having the same succinyl group were reacted in the same feeding ratio (Table 2). It is assumed that a large oligopeptide had lower reactivity than the corresponding small amino acid in the coupling reaction with a large dendrimer. The number of model peptides bound to the lactose-poly(lysine) dendrimer was not large, taking into account ordinarily high reactivity of a poly(lysine) dendrimer. This might be explained that the lactose residue on the surface of poly(lysine) dendrimer might have caused an intermolecular hydrogen bond between $\mathrm{OH}$ groups in neighboring lactose residues, which lowered the reactivity with $\mathrm{COOH}$ group as well as the solubility in organic solvents. In conclusion, an HIV vaccine model was successfully synthesized by binding an oligopeptide derivative to a lactose-poly(lysine) dendrimer through formation of an ester linkage. 


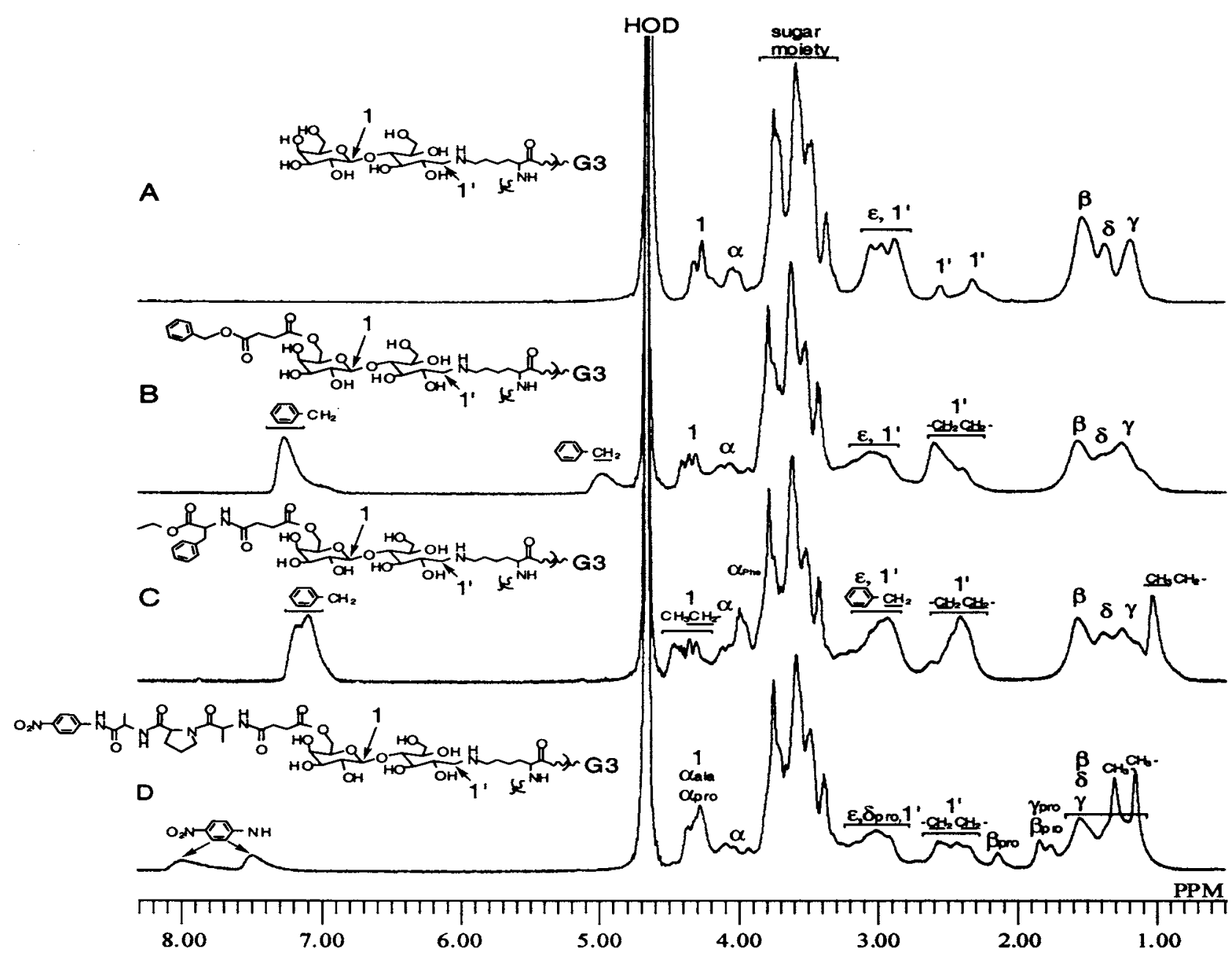

Fig. $5{ }^{1} \mathrm{H}$ NMR spectra of lactose-poly(lysine) dendrimer $\mathrm{G} 3$ and vaccine models in $\mathrm{D}_{2} \mathrm{O}$

(A: LLD; B: SBLD;C: PASLD; D: APASD).

Table 2 Synthesis of sugar-containing vaccine models using lactosepoly(lysine) dendrimer $\mathrm{G} 3$ and antigen model compounds. ${ }^{2}$ )

\begin{tabular}{|c|c|c|c|c|c|c|}
\hline \multirow{2}{*}{$\begin{array}{l}\text { vaccine } \\
\text { model }\end{array}$} & \multicolumn{2}{|c|}{ LLD $^{\text {b) }}$} & \multicolumn{2}{|c|}{ model compound } & \multirow{2}{*}{$\begin{array}{r}\text { yield } \\
\mathrm{mg}\end{array}$} & \multirow{2}{*}{$\begin{array}{l}\text { DS of model } \\
\text { portion })\end{array}$} \\
\hline & DS & $\mathrm{mg}$ & kind & equiv $^{c}$ ) & & \\
\hline SBLD $^{\text {e) }}$ & 19 & 80 & $S B^{f)}$ & 18 & 83 & 8 \\
\hline PASLD $^{\mathrm{g})}$ & 16 & 48 & PAS $^{\text {h) }}$ & 18 & 55 & 8 \\
\hline APASD $^{\text {i) }}$ & 19 & 53 & $\operatorname{APAS}^{\mathrm{j})}$ & 18 & 57 & 4 \\
\hline
\end{tabular}

a) The reaction was conducted in DMSO using DMAP and DCC as condensing agents. The temperature was r.t. The time was $24 \mathrm{~h}$.

${ }^{b)}$ Lactose-poly(lysine) dendrimer G3. ${ }^{\text {c) }}$ Equivalent to lactose-poly(lysine) dendrimer $\mathrm{G} 3 .{ }^{\mathrm{d})}$ The degree of substitution of antigen peptide model compound was calculated using ${ }^{1} \mathrm{H}$ NMR spectra. ${ }^{\text {e) }}$ Succinyl monobenzylate-lactose-poly(lysine) dendrimer G3. ${ }^{\mathrm{f}}$ Succinyl monobenzylate.

${ }^{\text {g) }}$ Ethyl-phenylalanyl succinylamide-lactose-poly (lysine) dendrimer G3.

${ }^{\text {h) }}$ Ethyl-phenylalanyl succinyamide. ${ }^{\text {i) }}$ Alanyl-prolyl-alanine-p-nitroanilidesuccinyl-lactose-poly(lysine) dendrimer $\mathrm{G} 3{ }^{\mathrm{j}}{ }^{\mathrm{j}}$ Succinyl-alanylprolyl-alanine p-nitroanilide. 


\section{References}

1. E. R. Gillies, J. M. Frechet, J. Am. Chem. Soc., 124, 14137 (2002).

2. D. A. Tomalia, A. M. Naylor, W. A. Goddard III, Angew. Chem. Int. Ed. Engl., 29, 138 (1990).

3. N. Jayaraman, S. A. Nepogodiev, J. F. Stoddart, Chem. Eur. J., 3, 1193 (1997).

4. G. R. Newkome, C. N. Moorefield, F. Vögtle, Dendritic Molecules. Concepts, Syntheses, Perspectives; VCH: Cambridge, England, 1996.

5. M. Okaniwa, K. Takeuchi, M. Asai, M. Ueda, Macromolecules, 35, 6224 (2002).

6. P. R. Ashton, S. E. Boyd, C. L. Brown, S. A. Nepogodiev, E. W. Meijer, H. W. I. Peerlings, J. F. Stoddart, Chem. Eur. J., 3, 974 (1997).

7. D. Page, R. Roy, Bioconjugate Chem., 8, 714 (1997).

8. S. Andre, P. J. C. Ortega, M. A. Perez, R. Roy, H. J. Gabius, Glycobiology, 9, 1253 (1999).

9. C. Kieburg, T. K. Lindhorst, Tetrahedron Lett., 38, 3885 (1997).

10. K. Aoi, K. Itoh, M. Okada, Macromolecules, 28, 5391 (1995).

11. K. Tsutsumiuchi, K. Aoi, M. Okada, Polym. J., 31,
935 (1999).

12. E. K. Woller, E. D. Walter, J. R. Morgan, D. J. Singel, and M. J. Cloninger, J. Am. Chem. Soc. 125, 8820 (2003).

13. H. Baigude, K. Katsuraya, K. Okuyama, Y. Yachi, S. Sato, T. Uryu, J. Polym. Sci. A Polym. Chem., 40, 3622 (2002).

14. H. Baigude, K. Kasturaya, K. Okuyama, S. Tokunaga, T. Uryu, Macromolecules, 36, 7100 (2003).

15. H. Baigude, K. Katsuraya, K. Okuyama, K. Hatanaka, E. Ikeda, N. Shibata, T. Uryu, J. Polym. Sci. A Polym. Chem. paper accepted.

16. H. Baigude, K. Katsuraya, K. Okuyama, T. Uryu, Macromol. Chem. Phys., submitted.

17. N. Malik, R. Wiwattanapatapee, R. Klopsch, K. Lorenz, H. Frey, J. W. Weener, E. W. Meijer, W. Paulus, R. Duncan, J. Controlled Release, 65, 133 (2000).

18. S. Supattapone, H. Wille, L. Uyechi, J. Safar, P. Tremblay, F. C., Jr. Szoka, F. E. Cohen, S. B. Prusiner, M. R. Scott, J. Virol., 75, 3453 (2001).

19. Unpublished results. 